\title{
Simple sugar supplementation abrogates exercise-induced increase in hepcidin in young men
}

\author{
Maja Tomczyk ${ }^{1}$, Jakub Kortas ${ }^{2}$, Damian Flis ${ }^{3}$, Wojciech Skrobot ${ }^{4}$, Rafal Camilleri ${ }^{1}$ and Jedrzej Antosiewicz ${ }^{*}$ (D)
}

\begin{abstract}
Background: At present many young people experience too much body iron accumulation. The reason of this phenomenon is not clear. There is accumulating evidences that not proper diet and lack of exercise could be a main contributing factors. This investigation assessed the effects of a diet rich in simple sugars (glucose or fructose) on exercise-induced hepcidin which is hormone regulating iron metabolism.
\end{abstract}

Methods: A group of physically active young men completed an incremental exercise test before and after a 3-day diet supplemented with fructose (4 g/kg BM) or glucose (4 g/ $/ \mathrm{kg} \mathrm{BM).} \mathrm{After} \mathrm{a} \mathrm{1-week} \mathrm{break,} \mathrm{they} \mathrm{crossed} \mathrm{over} \mathrm{to}$ the alternate mode for the subsequent 3-days period. Venous blood samples were collected before and after $1 \mathrm{~h}$ exercise and were analysed for serum hepcidin, IL-6, CRP, iron, and ferritin. The physiological response to exercise was also determined.

Results: The concentration of hepcidin increased $1 \mathrm{~h}$ after exercise for the baseline test $(p<0.05)$, whereas no changes in hepcidin were observed in men whose diet was supplemented with fructose or glucose. Blood IL-6 increased significantly after exercise only in subjects supplemented with fructose. Changes in hepcidin did not correlate with shifts in serum IL-6.

Conclusions: These data suggest that protective effects of exercise on excess iron accumulation in human body which is mediated by hepcidin can be abrogated by high sugar consumption which is typical for contemporary people.

Keywords: Iron, Metabolism, Ferritin, CRP, Diet

\section{Background}

Iron plays a key role in most of processes in the human body, including respiration, DNA biosynthesis, regulation of gene expression and many others. Metabolically active iron is a component of enzymes, including enzymes involved in DNA synthesis, mitochondrial and detoxifying enzymes and many more [1]. This could be the reason why many people think that if we consume or accumulate more iron is better. It is important to note that iron can be very toxic. The involvement of iron in many physiological processes is mainly related to its ability to gain and lose electrons. For example, iron in the mitochondrial respiratory chain, as a part of cytochromes, transfers

\footnotetext{
* Correspondence: jant@gumed.edu.pl

'Department of Biochemistry, Gdansk University of Physical Education and

Sport, Kazimierza Gorskiego 1, 80-336 Gdansk, Poland

Full list of author information is available at the end of the article
}

electrons from NADH to oxygen. Conversely, free iron can stimulate the formation of reactive oxygen species and participate in damage to cellular structures, such as DNA, lipids or proteins [2]. Iron has been shown to mediated inflammation process induced by exercise [3]. Ferritin is a protein that stores iron and protects against its toxicity. In addition, an increase in free iron, also called the labile iron pool (LIP), induces an adaptive response, which leads to an increase in intracellular ferritin [4]. Despite this, there are several reports demonstrating that stored iron can have deleterious effects on human health and fitness $[2,5]$. For example, high body iron stores were associated with low cardiovascular fitness in young men [6]. The exact mechanism of iron toxicity is not well understood, but iron bound to transferrin or ferritin does not stimulate reactive oxygen species (ROS) formation. However, non-transferrin bound iron was observed in 
diabetic persons [7]. In addition, experiments performed in cell culture or animals demonstrated that during stress conditions when protein kinases are activated, ferritin undergoes degradation, leading to the release of iron and increased iron-dependent ROS formation [8]. These and other studies indicate two important things: first that stored iron is not safe and second that the amount of stored iron can determine its toxicity [9]. Therefore, identifying the mechanism responsible for excess iron accumulation may be crucial for a better understanding of the pathomechanisms of iron-related morbidities.

Among factors that can influence body iron accumulation, are exercise and diet.

A diet rich in iron may certainly contribute to iron accumulation. Moreover, there are reports demonstrating that simple sugars can influence intestinal iron absorption, thereby modifying body iron stores. For example, animals on diets supplemented with fructose accumulate more iron in the liver. Because the diet of modern people is reach in sugar, mainly due to the high consumption of soft drinks and added sugar in many foods, it is important to know its effects on iron metabolism.

Conversely, exercise may cause a decrease in body iron stores. For example, decrease in body iron stores was observed in elderly women after 32 weeks of Nordic walking training [10]. By contrast, physical inactivity, which has been recognized as epidemic in modern societies, may also have an impact on iron metabolism [11, 12]. Regular exercise reduces body iron stores; therefore, the lack of exercise may be responsible for body iron accumulation $[10,13]$. The effect of exercise on iron metabolism may be mediated by an increase in the hepcidin concentration [14]. Hepcidin is a 25 aa peptide that inhibits intestinal iron absorption or its release from storage tissues, such as the liver and other organs [15]. The purpose of this study was to re-examine the role of simple sugar in a diet on exercise induced changes in iron metabolism.

Any factor that modifies the effects of exercise on blood hepcidin may contribute to impaired iron metabolism. In our study, we hypothesized that a diet rich in simple sugars (glucose and fructose) may modify the effect of exercise on blood hepcidin.

Furthermore, blood ferritin is a good marker of body iron stores if inflammation is not present.

\section{Methods}

\section{Subjects}

The study involved 17 healthy, physically active but not highly trained, college-aged men (Table 1). The study protocol used a randomised, crossover, blind design. Study subjects performed exercise test after 3 days of control diet and then were randomised to either 3 days of diet supplemented with fructose $(4 \mathrm{~g} / \mathrm{kg} \mathrm{BM})$ or glucose $(4 \mathrm{~g} / \mathrm{kg} \mathrm{BM})$, and then after a 1 -week break, crossed
Table 1 Anthropometric and physiological characteristics of participants $(n=17)$

\begin{tabular}{lllllll}
\hline Variable & $X$ & SD & Me & $V$ & \multicolumn{2}{c}{ Confidence interval } \\
\cline { 5 - 7 } & & & & & $-95 \%$ & $+95 \%$ \\
\hline Age [years] & 21,12 & 1,11 & 21 & 5,26 & 20,55 & 21,69 \\
Weight [kg] & 77,6 & 5,56 & 77,3 & 7,17 & 74,74 & 80,46 \\
Height [cm] & 183 & 5,36 & 183 & 2,93 & 180,24 & 185,76 \\
Fat [\%] & 12,21 & 3,34 & 10,8 & 27,4 & 10,49 & 13,92 \\
FFM [kg] & 68,19 & 6,28 & 69,2 & 9,21 & 64,97 & 71,42 \\
TBW [kg] & 49,95 & 4,59 & 50,6 & 9,2 & 47,59 & 52,31 \\
VO $_{2 \text { max }}\left[\mathrm{mL} \cdot \mathrm{kg}^{-1} \cdot \mathrm{min}^{-1}\right.$ ] & 51,06 & 8,9 & 49 & 17,43 & 46,48 & 55,63
\end{tabular}

Abbreviations: $X$ means, $S D$ standard deviation, Me median, $V$ coefficient of variation, BMI Body Mass Index, Fat fat mass, Fat \% percentage of body fat, FFM free fat mass, TBW total body water, VO2max maximal oxygen uptake expressed in relatively values, Pmax maximal power

over to the alternate mode for the subsequent 3-day period. During the 1-week break participants maintained they daily routines and diet was not control. The participants were fully informed and gave written informed consent to participate in this study as approved by the Medical Research Ethics Committee of the Medical University of Gdansk in Poland. Details that might disclose the identity of the subjects under study have been omitted.

\section{Diet}

The nutritional components of the diet are presented in Table 1 Participants ate 5 meals a day at set times over a period of 3 days. The respondents declared that they would not eat other meals than those that fall within the scope of the study. The daily value of the diet was $3541.90 \mathrm{kcal}$ $(14,819.66 \mathrm{~kJ})$ (Table 2). One hour before the start of the test, all participants received a breakfast with energy $613 \mathrm{kcal}(2565 \mathrm{~kJ})$. The nutritional value of the meals was estimated using the dietary calculator Nutritionist 2012 (Software Jumar 2012), based on the nutritional value determined by Polish Institute Food and Nutrition.

\section{Aerobic test}

The aerobic test was performed at the beginning of the study after 3 days of diet which was the same for all of the participants. Then after 3 days of sugar supplementation. The study design is presented in Fig. 1. Maximal oxygen uptake (VO2 max) was determined using a cycle

Table 2 The nutritional and energy value of 3-day diet (without drinks)

\begin{tabular}{ll}
\hline Energy value (kcal) & 3541.90 \\
Carbohydrates (g) & 589.9 \\
Proteins (g) & 156.3 \\
Fat (g) & 72.2 \\
Fibre (g) & 30.3 \\
\hline
\end{tabular}




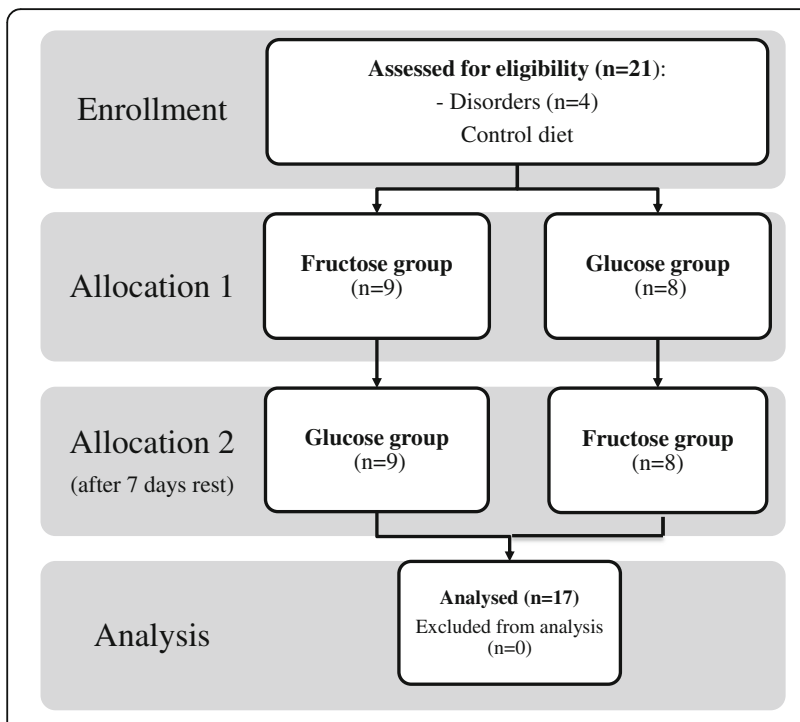

Fig. 1 Schematic presentation of the experimental design

\section{Effect of fructose and glucose supplementation on blood hepcidin}

To evaluate the effect of fructose or glucose supplementation on iron metabolism, the subjects underwent an exercise test to exhaustion and the blood hepcidin was then measured. As shown in Fig. 2, exercise induced a significant increase in blood hepcidin in subjects who were on the diet without supplementation (placebo). Conversely, no changes in hepcidin concentration were observed in subjects whose diet was supplemented with fructose or glucose. Notably, 3 days of diet supplemented with fructose or glucose did not influence the resting blood hepcidin.

Hepcidin biosynthesis is stimulated by IL-6; therefore, its concentration was evaluated before and after exercise. Exercise induced a significant increase in IL-6 in the fructose group and had no effects in the G group. A small increase in IL-6 was observed in the placebo group; however, the changes were not significant (Fig. 3). Neither exercise nor diet had effect on blood CRP concentration (Fig. 4).

\section{Discussion}

In the present study, we demonstrated that a diet rich in simple sugars, fructose or glucose modulates iron metabolism in young men. Sugar can stimulate intestinal iron absorption; however, the mechanism of this has not been fully elucidated [16]. It is proposed that fructose increases dietary non-heme iron absorption, possibly by chelating and/or reducing iron into the ferrous form [17].

Many scientific papers state that iron deficiency is the most common nutrition deficit in the world. Conversely, in the Western world, iron overload is much more common than iron deficiency. For example, a study performed on elderly subjects demonstrated that $12.9 \%$ of the studied population were iron overloaded (serum

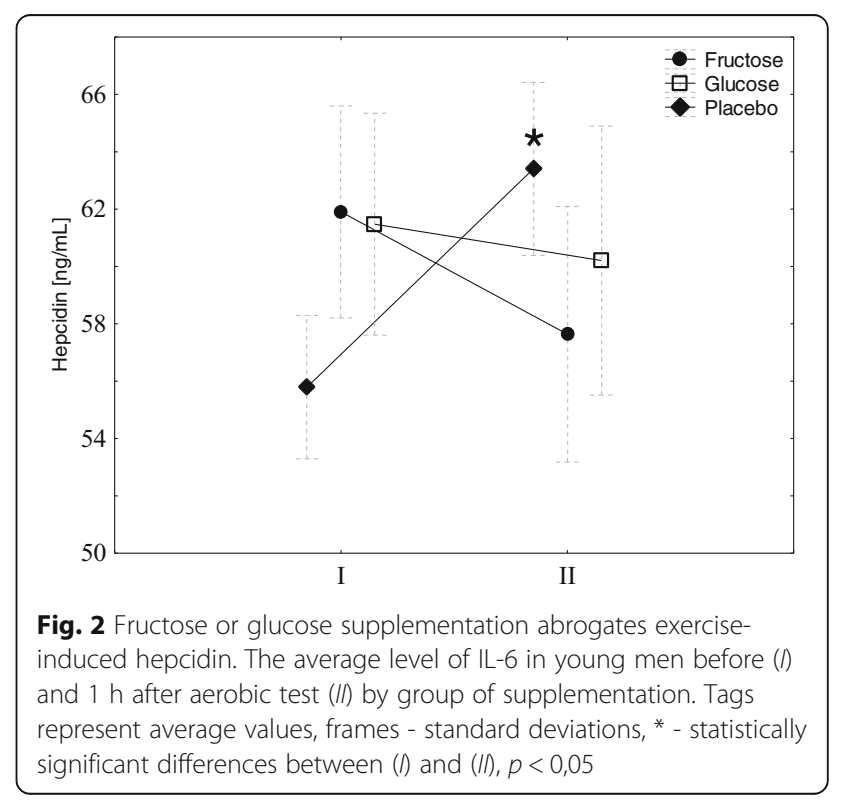

\section{Blood analysis}

A professional nurse collected blood samples. Samples were obtained from an antecubital vein into single-use containers with an anticoagulant (EDTA K2) before and $1 \mathrm{~h}$ after the aerobic test. The serum hepcidin levels were determined using a DRG ELISA kit CRP, IL6.

\section{Results}

Of the 21 subjects who were enrolled in the study, four were excluded because of failure to complete the second exercise test (Fig. 1). Therefore, only 17 subjects are included in the analyses. No difference was observed between fructose vs glucose supplementation in the dietary intake for total kilocalories, total grams of protein, or percentage protein. As discussed it the methods, they remained on the same diet for 3 days before the exercise test. 


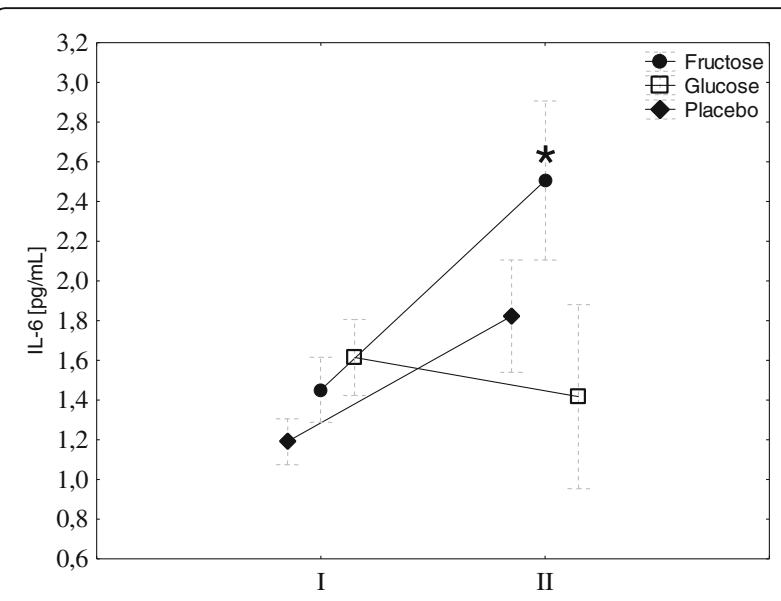

Fig. 3 Fructose supplementation augments exercise-induced IL-6. The average level of IL-6 in young men before ( $/$ ) and $1 \mathrm{~h}$ after aerobic test (I/) by group of supplementation. Tags represent average values, frames - standard deviations, ${ }^{*}$ - statistically significant differences between $(I)$ and $(I I), p<0,05$

ferritin (SF) $>300 \mu \mathrm{g} / \mathrm{L}$ in men and $200 \mu \mathrm{g} / \mathrm{L}$ in women), whereas only $3 \%$ were iron deficient (SF $<12 \mu \mathrm{g} / \mathrm{L}$ ) [18].

A study performed on young men demonstrated that most had blood ferritin concentrations above $150 \mu \mathrm{g} / \mathrm{L}$ and this was associated with low cardiovascular fitness [6]. The authors estimated that in the USA alone, approximately 24.8 $\mathrm{M}$ young men could have ferritin above this value. Notably, ferritin the reference value is 16 to $300 \mu \mathrm{g} / \mathrm{L}$; however, an increasing number of studies have demonstrated that persons with ferritin above $100 \mu \mathrm{g} / \mathrm{L}$ are at risk for several morbidities, including cancer diabetes, heart attack and others [19-21]. Therefore, it is important to determine the reason for excess iron accumulation in so many people. Certainly, diet and exercise are two important determinants

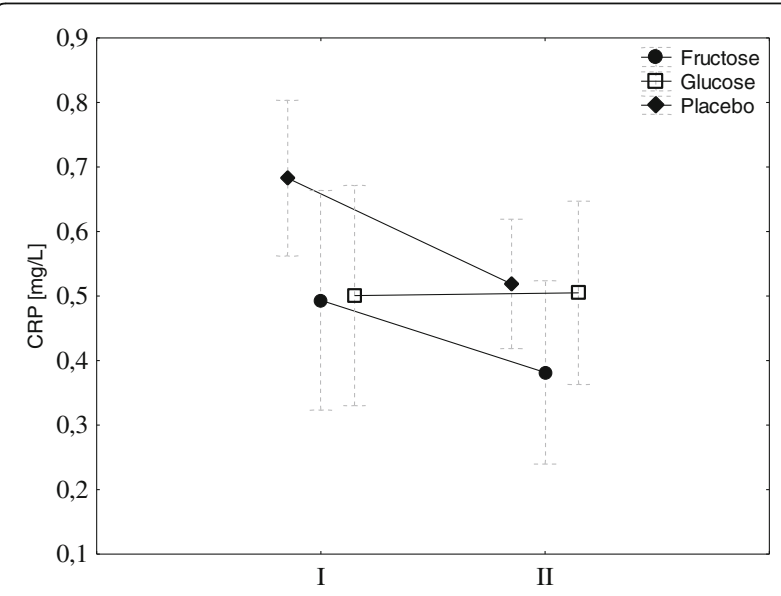

Fig. 4 Fructose or glucose supplementation has no effect on CRP. The average level of CRP in young men before $(I)$ and $1 \mathrm{~h}$ after aerobic test (II) by group of supplementation. Tags represent average values, frames - standard deviations of iron status. Recently, we demonstrated that regular training reduced body iron stores in the elderly [10]. Moreover, highly trained young men are characterised by lower body iron stores compared to untrained young men [14]. Why regular training reduces body iron stores is not precisely understood; however, an increase in blood hepcidin may be an important cause. A single exercise session can lead to an increase in blood hepcidin, [14, 22] which can lead to lower intestinal iron absorption because it blocks ferroportin, a protein that exports iron from enterocytes into blood [15].

High sugar consumption is typical for highly developed countries. The average sugar consumption in the United States is approximately $70 \mathrm{~kg}$ per person per year [23]. A diet rich in sugar may increase physical performance by stimulating glycogen biosynthesis. This is one reason why many athletes consume sugar-rich diets. If super compensation of glycogen is to be achieved, the diet should contain approximately $70 \%$ carbohydrates. Unfortunately, often sweets or other products rich in sucrose or simple sugars are an essential part of the athlete diet. This is why this study diet was supplemented with fructose or glucose. Doses of $4 \mathrm{~g} / \mathrm{kg}$ body weight per day were applied. Here, we present evidence that supplementation of the diet with fructose or glucose abrogates the increase in blood hepcidin after exercise. It was previously reported that not all subjects respond the same way; therefore, they were divided into responders and nonresponders, those whose blood hepcidin increased or did not change after exercise, respectively. The reasons for this are not known. Peeling and co-workers suggested that it is due to the difference in body iron stores, and persons with low iron stores do not respond to exercise by increasing hepcidin biosynthesis. Consistent with this, blood hepcidin did not change after $100 \mathrm{~km}$ in runners who were also characterized by relatively low ferritin levels $(53 \mu \mathrm{g} / \mathrm{L})$ [24]. The results of this study indicate that the difference could be a result of the diet.

Exercise stimulates IL-6 release from skeletal muscle and induces hepcidin biosynthesis in the liver [25]. We observed that exercise significantly increased the IL-6 concentration only in subjects whose diet was supplemented with fructose. If it is, consider that IL-6 is a skeletal muscle origin [26] these data suggest that fructose has some effect on muscle metabolism distinct than glucose. In addition it rather excludes the role of IL- 6 in inducing an increase in hepcidin after exercise and are consistent our previous studies on ultra-marathoners in whom an increase in IL-6 was not accompanied by changes in blood hepcidin [24].

\section{Conclusion}

In conclusion, this study demonstrated that high consumption of fructose or glucose abrogates the exercise-induced increase in blood hepcidin. These data suggest that high sugar is a reason for excess body iron accumulation. 


\section{Abbreviations}

BM: Body mass; LIP: Labile iron pool; ROS: Reactive oxygen species; SF: Serum ferritin; VO2: Max maximal oxygen uptake

\section{Acknowledgements}

We would like to express our thanks to whole team and all students for their engagement in the experiment.

\section{Funding}

The experiment was founded by knowledge grant of Polish Ministry of Science and Higher Education No 0016/RS2/2013/52.

\section{Availability of data and materials}

Data are all contained within the article.

\section{Authors' contributions}

MT design and control the diet, participated in the hepcidin measurment, drafted the manuscript. JK participated in the design of the study and performed the statistical analysis DF carried out the elisa measurments. WS participated in the designe of the study and helped to draft the manuscript. RC participated in design and helped to draft the manuscript. JA participated in design and helped to draft the manuscript. All authors read and approved the final manuscript.

\section{Competing interests}

The authors declare that they have no competing interests.

\section{Consent for publication}

Consent to publish has been obtained from the participant to report individual patient data.

\section{Ethics approval and consent to participate}

The participants were fully informed and gave written informed consent to participate in this study as approved by the Medical Research Ethics Committee of the Medical University of Gdansk in Poland. Details that might disclose the identity of the subjects under study have been omitted.

\section{Publisher's Note}

Springer Nature remains neutral with regard to jurisdictional claims in published maps and institutional affiliations.

\section{Author details}

'Department of Biochemistry, Gdansk University of Physical Education and Sport, Kazimierza Gorskiego 1, 80-336 Gdansk, Poland. ${ }^{2}$ Department of Recreation and Qualify Tourism, Gdansk University of PhysicalEducation and Sport, Kazimierza Górskiego 1, 80-336 Gdansk, Poland. ${ }^{3}$ Department of Bioenergetics and Physiology of Exercise, Medical University of Gdansk, Gdansk, Poland. ${ }^{4}$ Department of Physiotherapy, University of Physical Education and Sport, Kazimierza Gorskiego, Gdańsk, Poland.

\section{Received: 21 October 2016 Accepted: 14 April 2017}

Published online: 20 April 2017

\section{References}

1. Alaunyte I, Stojceska V, Plunkett A, Derbyshire E. Dietary iron intervention using a staple food product for improvement of iron status in female runners. J Int Soc Sports Nutr. 2014;11:50.

2. Kell DB. Iron behaving badly: inappropriate iron chelation as a major contributor to the aetiology of vascular and other progressive inflammatory and degenerative diseases. BMC Med Genomics. 2009;2:2.

3. Punduk Z, Oral O, Ozkayin N, Rahman K, Varol R. Single dose of intra-muscular platelet rich plasma reverses the increase in plasma iron levels in exerciseinduced muscle damage: a pilot study. J Sport Health Sci. 2016;5:109-14.

4. Kruszewski M. Labile iron pool: the main determinant of cellular response to oxidative stress. Mutat Res. 2003:531:81-92.

5. Howard CT, Mckakpo US, Quakyi IA, Bosompem KM, Addison EA, Sun K Sullivan D, Semba RD. Relationship of hepcidin with parasitemia and anemia among patients with uncomplicated plasmodium falciparum malaria in Ghana. Am J Trop Med Hyg. 2007;77:623-6.

6. Mainous 3rd AG, Diaz VA. Relation of serum ferritin level to cardiovascular fitness among young men. Am J Cardiol. 2009;103:115-8.
7. Lee DH, Liu DY, Jacobs Jr DR, Shin HR, Song K, Lee IK, Kim B, Hider RC Common presence of non-transferrin-bound iron among patients with type 2 diabetes. Diabetes Care. 2006;29:1090-5.

8. Antosiewicz J, Ziolkowski W, Kaczor JJ, Herman-Antosiewicz A. Tumor necrosis factor-alpha-induced reactive oxygen species formation is mediated by jnk1-dependent ferritin degradation and elevation of labile iron pool. Free Radic Biol Med. 2007;43:265-70.

9. Sullivan JL. Is stored iron safe? J Lab Clin Med. 2004;144:280-4.

10. Kortas J, Prusik K, Flis D, Prusik K, Ziemann E, Leaver N, Antosiewicz J. Effect of Nordic walking training on iron metabolism in elderly women. Clin Interv Aging. 2015;10:1889-96.

11. Lee IM, Shiroma EJ, Lobelo F, Puska P, Blair SN, Katzmarzyk PT, Lancet Physical Activity Series Working G. Effect of physical inactivity on major non-communicable diseases worldwide: an analysis of burden of disease and life expectancy. Lancet. 2012;380:219-29.

12. Li L. The financial burden of physical inactivity. J Sport Health Sci. 2014;3:58-9.

13. Lakka TA, Nyyssonen K, Salonen JT. Higher levels of conditioning leisure time physical activity are associated with reduced levels of stored iron in Finnish men. Am J Epidemiol. 1994;140:148-60.

14. Antosiewicz J, Kaczor JJ, Kasprowicz K, Laskowski R, Kujach S, Luszczyk M, Radziminski L, Ziemann E. Repeated "all out" interval exercise causes an increase in serum hepcidin concentration in both trained and untrained men. Cell Immunol. 2013;283:12-7.

15. Nemeth E, Tuttle MS, Powelson J, Vaughn MB, Donovan A, Ward DM, Ganz T, Kaplan J. Hepcidin regulates cellular iron efflux by binding to ferroportin and inducing its internalization. Science. 2004;306:2090-3.

16. Charley PJ, Sarkar B, Stitt CF, Saltman P. Chelation of iron by sugars. Biochim Biophys Acta. 1963;69:313-21.

17. O'Dell BL. Fructose and mineral metabolism. Am J Clin Nutr. 1993;58:771S-8S

18. Fleming DJ, Tucker KL, Jacques PF, Dallal GE, Wilson PW, Wood RJ. Dietary factors associated with the risk of high iron stores in the elderly Framingham heart study cohort. Am J Clin Nutr. 2002;76:1375-84

19. Zacharski LR, Chow BK, Howes PS, Shamayeva G, Baron JA, Dalman RL, Malenka DJ, Ozaki CK, Lavori PW. Decreased cancer risk after iron reduction in patients with peripheral arterial disease: results from a randomized trial. J Natl Cancer Inst. 2008;100:996-1002.

20. Salonen JT, Nyyssonen K, Korpela H, Tuomilehto J, Seppanen R, Salonen R. High stored iron levels are associated with excess risk of myocardial infarction in eastern Finnish men. Circulation. 1992:86:803-11.

21. Tuomainen TP, Nyyssonen K, Salonen R, Tervahauta A, Korpela H, Lakka T, Kaplan GA, Salonen JT. Body iron stores are associated with serum insulin and blood glucose concentrations. Population study in 1,013 eastern Finnish men. Diabetes Care. 1997;20:426-8.

22. Peeling P, Sim M, Badenhorst CE, Dawson B, Govus AD, Abbiss CR, Swinkels DW, Trinder D. Iron status and the acute post-exercise hepcidin response in athletes. Plos One. 2014;9:e93002.

23. Johnson RJ, Segal MS, Sautin Y, Nakagawa T, Feig DI, Kang DH, Gersch MS, Benner S, Sanchez-Lozada LG. Potential role of sugar (fructose) in the epidemic of hypertension, obesity and the metabolic syndrome, diabetes, kidney disease, and cardiovascular disease. Am J Clin Nutr. 2007:86:899-906.

24. Kasprowicz K, Ziemann E, Ratkowski W, Laskowski R, Kaczor JJ, Dadci R, Antosiewicz J. Running a 100-km ultra-marathon induces an inflammatory response but does not raise the level of the plasma iron-regulatory protein hepcidin. J Sports Med Phys Fitness. 2013;53:533-7.

25. Nemeth E, Rivera S, Gabayan V, Keller C, Taudorf S, Pedersen BK, Ganz T. II-6 mediates hypoferremia of inflammation by inducing the synthesis of the iron regulatory hormone hepcidin. J Clin Invest. 2004;113:1271-6.

26. Pedersen BK, Febbraio M. Muscle-derived interleukin-6-a possible link between skeletal muscle, adipose tissue, liver, and brain. Brain Behav Immun. 2005;19:371-6. 